\title{
Species- and sex-specific differences in foraging behaviour and foraging zones in blue-footed and brown boobies in the Gulf of California
}

\author{
Henri Weimerskirch ${ }^{1, *}$, Scott A. Shaffer ${ }^{2}$, Yann Tremblay ${ }^{2}$, Daniel P. Costa ${ }^{2}$, \\ Hélène Gadenne $^{1}$, Akiko Kato ${ }^{3,6}$, Yan Ropert-Coudert ${ }^{3,6}$, Katsufumi Sato ${ }^{4}$, \\ David Aurioles ${ }^{5}$ \\ ${ }^{1}$ Centre d'Etudes Biologiques de Chizé, Centre National de la Recherche Scientifique, 79360 Villiers en Bois, France \\ ${ }^{2}$ Ecology \& Evolutionary Biology, University of California Santa Cruz, Santa Cruz, California 95060, USA \\ ${ }^{3}$ National Institute of Polar Research, 1-9-10 Kaga, Itabashi-ku, Tokyo 173-8515, Japan \\ ${ }^{4}$ International Coastal Research Center, Ocean Research Institute, The University of Tokyo, 2-106-1 Akahama, Otsuchi, \\ Iwate 028-1102, Japan \\ ${ }^{5}$ Departamento de Pesquerias y Biologia Marina, CICIMAR-IPN, La Paz, B.C.S., Mexico
}

${ }^{6}$ Present address: Institut Pluridisciplinaire Hubert Curien, Centre National de la Recherche Scientifique,67037 Strasbourg, France

\begin{abstract}
When 2 closely related species co-occur, each exhibiting sex-specific differences in size, resource partitioning is expected. We studied sex-specific foraging behaviour of 2 sympatric seabird species in the Gulf of California to disentangle the respective influence of species and sex, but also mass and size of individuals, on observed foraging behaviour. We used highly accurate data loggers to study movements, diving behaviour and activity of brown and blue-footed boobies rearing young chicks. Interspecific differences were limited; brown boobies had longer foraging trips and spent less time on the water than blue-footed boobies. The major differences observed were sex-specific; females of each species tended to have longer foraging trips, foraged farther from the colony, flew greater distances and had larger zones of area-restricted search. These sex-specific differences were more prominent in brown than in blue-footed boobies. Diet and stable isotope analyses showed that, during the study period, both species fed mainly on sardines, at similar trophic levels and in similar zones; outside the breeding season, the carbon and nitrogen signatures from feathers were also similar on average. In these sympatric species that feed on a superabundant prey, sex-specific differences appear to have a greater role than species-specific differences. We suggest that sex-specific differences may be mainly related to breeding involvement, as males are more involved in nest attendance and defence and females are greater provisioners. However, we show that several sex-specific differences in observed foraging behaviour were partly or totally explained by body size (flight speeds, foraging range, flapping frequency) or by body mass (depths attained during diving, duration of dives), which are parameters influenced by biomechanical constraints such as flight and diving.
\end{abstract}

KEY WORDS: Accelerometers · GPS tracking $\cdot$ Sula leucogaster $\cdot$ Sula nebouxii $\cdot$ Area-restricted search $\cdot$ Fractal landscape method $\cdot$ Diet $\cdot$ Isotopes

\section{INTRODUCTION}

Understanding how closely related species can coexist has been a long-lasting subject of research (e.g. Pianka 1981, Ricklefs 1990). When species breed sym- patrically, niche differentiation is expected at equilibrium. Partitioning of food sources can occur in sympatric species by differential selection of foraging habitat, foraging strategy or prey choice. Body size differences between species may also favour niche dif- 
ferentiation (Bowers \& Smith 1979, Clutton-Brock et al. 1987, Andersson 1994, LeBoeuf et al. 2000). Within species, body size differences between sexes are common, and the extent of the difference in size varies extensively according to the taxa considered (Andersson 1994). Three major hypotheses have been proposed to explain the evolution of sexual size dimorphism: (1) sexual selection, (2) intersexual food competition, and (3) reproductive role division, and empirical studies have demonstrated that each of the 3 mechanisms operates in natural populations (Hedrick \& Temeles 1989). Sex differences in food and foraging ecology have often been proposed as important factors leading to the evolution of size dimorphism between sexes (Andersson \& Norberg 1981, Shine 1989, Mueller 1990), and many empirical studies have highlighted such differences (e.g. Selander 1966, Schoener 1967, Pierotti 1981, Le Boeuf et al. 2000, Cook et al. 2007). Apart from diet, it is often difficult to study foraging behaviour in many fast-moving or wide-ranging animals under natural conditions. Therefore, we generally lack information on the way sexes or species can differ in their foraging behaviour, such as movement, techniques or effort, which limits our ability to relate foraging and body size differences.

In birds, where flight is strongly constrained by physics, and in particular by structural size and mass, body size differences between sexes are less exaggerated than in mammals and reptiles (Andersson 1994). Although not as prominent, sexual dimorphism occurs in many bird taxa where males are larger than females, and the differences have most often been related to sexual selection. Reversed size dimorphism (referred to as reversed sexual dimorphism, RSD) also exists among several avian taxa. In species exhibiting sexual size dimorphism, significant differences in foraging behaviour have been found (e.g. Newton 1979). Within a particular taxonomic family, the extent of sexual dimorphism can vary according to species, suggesting that mechanisms leading to the evolution of dimorphic patterns within a family should vary in their extent. In the hypothesis that sexual dimorphism is related to foraging behaviour, the extent of niche partitioning and congruent differences in foraging behaviour between 2 species are expected to differ in proportion to sexual dimorphism. Thus, when examining the evolution of size dimorphism and its relationship with foraging behaviour, it is of particular interest to compare the respective influence of species, sex and the degree of size difference on the foraging behaviour of closely related species. However, this has rarely been done (e.g. Paredes et al. 2008).

In seabirds, males and females have similar roles when breeding, plumage characteristics are generally similar between the sexes, and sexual dimorphism is not extensive compared to other species of birds. Nevertheless, sex-specific differences in foraging behaviour have been found in several species with pronounced sexual dimorphism (Weimerskirch et al. 1993, 2006, Kato et al. 1999, González-Solís et al. 2000a,b, Phillips et al. 2004), but also in species with no size dimorphism (Gray \& Hamer 2001, Lewis et al. 2002). These latter examples suggest that differences in foraging behaviour may not always be related to the maintenance of sexual size dimorphism (Lewis et al. 2005). RSD is also found in several seabird families such as boobies, frigatebirds and skuas. In boobies, sex differences in foraging behaviour have been found in several species (Lewis et al. 2005, Weimerskirch et al. 2006, Zavalaga et al. 2007), and the degree of difference appears to match the extent of sexual dimorphism for some foraging parameters such as dive depths or foraging duration (Lewis et al. 2005).

In the present study, we examined sex differences in the foraging behaviour of 2 sympatric booby species of different body size, each species presenting RSD with extensive size dimorphism. We studied brown boobies Sula leucogaster brewsteri and blue-footed boobies $S$. nebouxii breeding on an island in the Gulf of California, using (1) highly accurate miniaturised GPS data loggers to examine the spatial distribution and foraging movements of each species and sex, and (2) data loggers that measured diving depth and acceleration to study the details of the diving behaviour and timebudget activity. In addition, diet differences between study groups were examined by collecting regurgitated stomach contents, and stable isotopes were studied from blood and feather samples. Our primary objective was to examine whether both species differed in their foraging behaviour, and whether foraging behaviour differed between sexes within each species. Because one species is smaller than the other, and in contrast to the approach of Lewis et al. (2005), who tested sexual differences within 2 species, one with a higher degree of sexual dimorphism than the other, we chose to investigate differences along a gradient of individuals ranging from small male brown boobies, medium-sized female brown and male blue-footed boobies, and larger female blue-footed boobies. This setting allowed us to disentangle the respective roles of each species-sex combination in foraging behaviour at this breeding colony, while taking into account the influence of size and mass on foraging parameters.

\section{MATERIALS AND METHODS}

The study was carried out on Isla San Ildefonso $\left(111.4^{\circ} \mathrm{W}, 26.6^{\circ} \mathrm{N}\right)$ in the Gulf of California, Mexico, between 3 and 12 March 2006. San Ildefonso is a $1 \mathrm{~km}$ 
long island located ca. $10 \mathrm{~km}$ from the eastern coast of the Baja California Peninsula. The island has mixed colonies of blue footed boobies (BFB) and brown boobies (BB) that breed in similar numbers, which we estimated to be 1000 to 2000 pairs for each species during our stay (see also W. G. Anderson in Nelson 1978, p. 520, who reported 800 to 1000 pairs in 1973 for bluefooted, but only a few pairs of brown boobies, which was supposedly abnormal for the species on this island). In March 2006, individuals of both species were mainly rearing small to large chicks, although some birds were still incubating eggs, which is in accordance with the winter breeding of the 2 species reported for the Gulf of California region (Nelson 1978, Mellink 2000). Our main study plot was located on the western side of the island, where most booby colonies occurred. Nests were localised during the day, but birds were captured only at night and solely when the moon was below the horizon to avoid predation of eggs and small unattended chicks by yellow-footed gulls Larus livens. Captures of birds for logger attachment or recovery upon completion of a foraging trip were made by hand or using a net. The exact duration of foraging trips was measured from GPS or accelerometer recordings.

At first capture, each bird was banded with a stainless steel identification band, measured (culmen length [Cl] in mm using dial callipers and wing length [Wl] in mm using a ruler), and weighed in a bag using a Pesola balance $( \pm 20 \mathrm{~g})$. Upon recapture for recovery of the data loggers, boobies were only weighed. An additional sample of 20 individuals was captured specifically to measure wingspan (Ws, in $\mathrm{cm}$ ) and wing area (Wa, in $\mathrm{cm}^{2}$ ) according to the methods developed by Pennycuick (1989), Hertel \& Ballance (1999) and Shaffer et al. (2001). From these measurements and the body mass (BM, in $\mathrm{g}$ ), we calculated the wing loading (an index of force per unit wing area in $\left.\mathrm{g} \mathrm{cm}^{-2}\right)$ as $\mathrm{W}_{\text {load }}=\mathrm{BM} \times g$ (gravitional acceleration, $9.81 \mathrm{~m} \mathrm{~s}^{-2}$ )/Wa, and the wing aspect ratio (an index of wing shape), as $\mathrm{W}_{\mathrm{ar}}=\mathrm{Ws}^{2} / \mathrm{Wa}$. Brown boobies were sexed by plumage characteristics (Nelson 1978), and $\mathrm{BFB}$, whose sexes are similar in terms of plumage, were sexed by vocal call (when captured, males have a higher pitched call than females; Nelson 1978). An index of size was calculated as the first principal component (PC1) of a principal component analysis performed on wing length and culmen length $(78.9 \%$ of the variance explained).

To study the foraging movements of boobies, we fitted 34 individuals (9 male BFB, 11 female BFB, 8 female $\mathrm{BB}$ and 6 male $\mathrm{BB}$ ) with a GPS receiver with integrated antenna and a 1 Mbyte flash memory operated by a rechargeable battery (Newbehavior; Steiner et al. 2000) recording at $10 \mathrm{~s}$ intervals. The loggers were sealed into small polyethylene bags. The overall weight of the device and its waterproof package was $32 \mathrm{~g}$ and measured ca. $38 \times 70 \mathrm{~mm}$. Loggers were deployed for 1 to $2 \mathrm{~d}$ on each bird before being retrieved, recording a total of 48 foraging trips. Activity patterns like flight and diving behaviour were studied using cylindrical, 4 channel data-loggers (M190D2GT, 12 bit resolution, $60 \times 15 \mathrm{~mm}, 20 \mathrm{~g}$, Little Leonardo) on 15 birds (9 BFB and $6 \mathrm{BB}$ ) for 1 to 3 trips each. The devices simultaneously monitored depth (every second), temperature (every minute) and acceleration (16 Hz) along 2 axes. The units contained a tilt sensor capable of measuring both dynamic (i.e. vibration) and static accelerations (i.e. gravity). Both types of loggers were attached to the birds' tail feathers so that acceleration was measured along the following 2 axes: surging acceleration was measured along the longitudinal body axis of a bird and heaving acceleration was measured dorso-ventrally (Watanuki et al. 2003, see also Ropert-Coudert et al. 2004). The relative accuracy of the depth sensor was $0.1 \mathrm{~m}$. GPS and accelerometers were taped under the 3 central tail feathers using Tesa ${ }^{\circledR}$ tape. Only one logger type was attached to a bird (either accelerometer or GPS), and the maximum added weight reached by an attached logger was $3 \%$ of the bird's body mass (in the case of a GPS). The locations and duration of time spent on the water were derived from GPS data when flight speeds were $<10 \mathrm{~km} \mathrm{~h}^{-1}$ (see Weimerskirch et al. 2005 and 'Results'). To estimate the foraging areas of boobies, we searched the tracks for the zones of arearestricted search (ARS, generally considered an indication of prey searching), when birds decreased flight speed and increased sinuosity, by using the fractal landscape method (Tremblay et al. 2007). This method allowed us to precisely quantify each ARS separately, in addition to estimating the size of each ARS and time spent within each ARS zone.

Boobies spontaneously regurgitate their stomach contents when handled, so 31 food samples were obtained from breeding adults caught at the nest after returning from sea. Samples were stored in plastic containers and frozen until identification of material in the laboratory. Samples were carefully inspected to identify fish or crustacean prey. Most of the material was digested, but some samples had fish in good enough shape to be identified or contained hard parts such as otoliths and urohial bones that were used to determine fish species. Otolith identification was made to the lowest possible taxon using photographs and diagrams (Fitch 1966, Fitch \& Brownell 1968) as well as the reference collection from the Centro Interdisciplinario de Ciencias Marinas (CICIMAR, La Paz, B.C.S., Mexico), which includes more than 100 species of fish from around Baja California. 
In addition to diet, we also collected feathers and blood samples for isotopic analyses. Blood was collected into a heparinised syringe by venipuncture of a brachial or tarsal blood vessel. Ethanol (70\%) was then added to whole blood as a preservative, which does not alter the isotopic composition of tissues (Hobson et al. 1997). The extremity ( 2 to $4 \mathrm{~cm}$ ) of 2 cover feathers was also collected and stored dry in plastic bags. Feathers were non-abraded fully-grown feathers, indicating they had been synthesised during the weeks/months before breeding. Blood and feather samples were subsequently kept at $-20^{\circ} \mathrm{C}$ and returned to the laboratory in La Paz, Mexico, for analysis. Feathers were rinsed with distilled water and then fully dried at $80^{\circ} \mathrm{C}$ for approximately $12 \mathrm{~h}$. Lipids were removed following the microwave-assisted extraction (MAE) protocol using a mixture of chloroform and methanol (1:1) (Bligh \& Dyer 1959). Feathers were subsequently dried and ground into a homogeneous fine powder. Serum samples were lyophilised and stored in a freezer prior to weighing sub-samples of $1.2 \pm 0.01 \mathrm{mg}$ of homogenised tissue. Both feather and serum samples were loaded into tin cups heated to $\mathrm{CO}_{2}$ and $\mathrm{N}_{2}$ at $1000^{\circ} \mathrm{C}$ in an on-line elemental analyser (PDZ Europa ANCA-GSL; Stable Isotope Laboratory, University of California, Davis) and analysed using a continuous flow isotope ratio mass spectrometer (20-20 PDZ Europa). The gases were separated on a Carbosieve G column (Supelco) before introduction to the IRMS. Ammonium sulphate $\left(\delta^{15} \mathrm{~N}=\right.$ $1.33 \%$ ) was used as a secondary standard for nitrogen, and sucrose $\left(\delta^{13} \mathrm{C}=-23.83 \%\right)$ was used for carbon.

Differences in isotopic composition were expressed in $\delta$ notation as the deviation from standards in parts per thousand (\%) according to the following equation: $\delta^{15} \mathrm{~N}$ or $\delta^{13} \mathrm{C}=\left[\left(R_{\text {sample }} / R_{\text {standard }}\right)-1\right] \times 1000$, where $R$ is the ratio of ${ }^{15} \mathrm{~N} /{ }^{14} \mathrm{~N}$ or ${ }^{13} \mathrm{C} /{ }^{12} \mathrm{C}$ for the sample and the standard, respectively. The international standards for stable isotope ratio analysis are atmospheric $\mathrm{N}_{2}$ (AIR) $\left(\delta^{15} \mathrm{~N}=0.004 \%\right.$ o) for nitrogen and Vienna Pee Dee Belemnite (VPDB) $\left(\delta^{13} \mathrm{C}=0.011 \%\right.$ ) for carbon. The analytical error indicated by replicate measurements of secondary standards was $\pm 0.2 \%$ for both nitrogen and carbon.

Statistical analyses were performed with STATISTICA 8 (StatSoft). Mean values are given \pm 1 SD. Because some individuals were tracked for multiple successive trips, we analysed foraging parameters using mixed-model analyses of variance (ANOVAs; module VEPAC in STATISTICA) to consider issues of pseudoreplication. Foraging parameters were taken as dependent variables, sex and species were added to the model as fixed factors and individual bird was included as a random factor. In a second step, we included the size (PC1) and body mass of individuals as a covariate in all analyses to examine whether individual size or mass was important after controlling for sex. Values for variables representing percentage were arcsine-transformed before performing ANOVAs.

\section{RESULTS}

\section{Body size and mass}

Within each species, females were 5 to $7 \%$ larger than males according to body measurements (except for tail length), and 18 to $21 \%$ according to body mass (Table 1). Between species, there was a gradient, with large female $\mathrm{BFB}$ at one end, small male $\mathrm{BB}$ at the opposite end, and intermediate and overlapping male BFB and female BB (Fig. 1, Table 1). There were no significant differences in wing loading or aspect ratio between the different categories; however, sample sizes were small.

\section{Foraging movement and habitat}

Foraging movements were similar between species, with a straight outward movement to one (or two in some individuals) sector considered a foraging zone, where birds changed flight direction regularly, followed by straight return movements (Fig. 2). Birds

Table 1. Sula leucogaster and S. nebouxii. Mass and morphometric measurements of male and female blue-footed and brown boobies. Values are mean \pm SD (sample size)

\begin{tabular}{|lccrrr|}
\hline & Males & Females & df & $F$ & $\mathrm{p}$ \\
\hline Blue-footed booby & & & & & \\
Culmen length (mm) & $106.7 \pm 4.6(22)$ & $113.1 \pm 3.6(22)$ & 42 & 25.5 & $<0.001$ \\
Wing length (mm) & $412.7 \pm 9.0(17)$ & $433.1 \pm 10.2(17)$ & 32 & 37.6 & $<0.001$ \\
Tail length (mm) & $238 \pm 3.0(2)$ & $232 \pm 17(2)$ & 3 & 0.37 & 0.585 \\
Wing loading (N m$\left.{ }^{-2}\right)$ & $75.5 \pm 5.4(3)$ & $72.9 \pm 3.2(7)$ & 8 & 0.9 & 0.365 \\
Aspect ratio & $12.3 \pm 0.4(3)$ & $12.2 \pm 0.6(7)$ & 8 & 0.1 & 0.742 \\
Wing span (cm) & $1576 \pm 29(3)$ & $1705 \pm 39(7)$ & 8 & 25.4 & $<0.001$ \\
Mass (g) & $1430 \pm 131(22)$ & $1811 \pm 105(22)$ & 42 & 112.5 & $<0.001$ \\
Brown booby & & & & & \\
Culmen length (mm) & $96.2 \pm 2.2(19)$ & $102.1 \pm 3.3(20)$ & 37 & 42.2 & $<0.001$ \\
Wing length (mm) & $393.5 \pm 15.7(15)$ & $419.1 \pm 8.1(14)$ & 27 & 29.6 & $<0.001$ \\
Tail length (mm) & $226 \pm 10(6)$ & $210 \pm 17(3)$ & 7 & 3.2 & 0.104 \\
Wing loading (N m$\left.{ }^{-2}\right)$ & $69.1 \pm 11.4(4)$ & $70.6 \pm 7.7(5)$ & 7 & 0.1 & 0.818 \\
Aspect ratio & $11.5 \pm 0.5(4)$ & $11.9 \pm 0.6(5)$ & 7 & 1.0 & 0.349 \\
Wing span $(\mathrm{cm})$ & $1431 \pm 11(4)$ & $1560 \pm 65(5)$ & 7 & 14.9 & 0.006 \\
Mass (g) & $1194 \pm 85(19)$ & $1448 \pm 86(20)$ & 37 & 86.2 & $<0.001$ \\
\hline
\end{tabular}




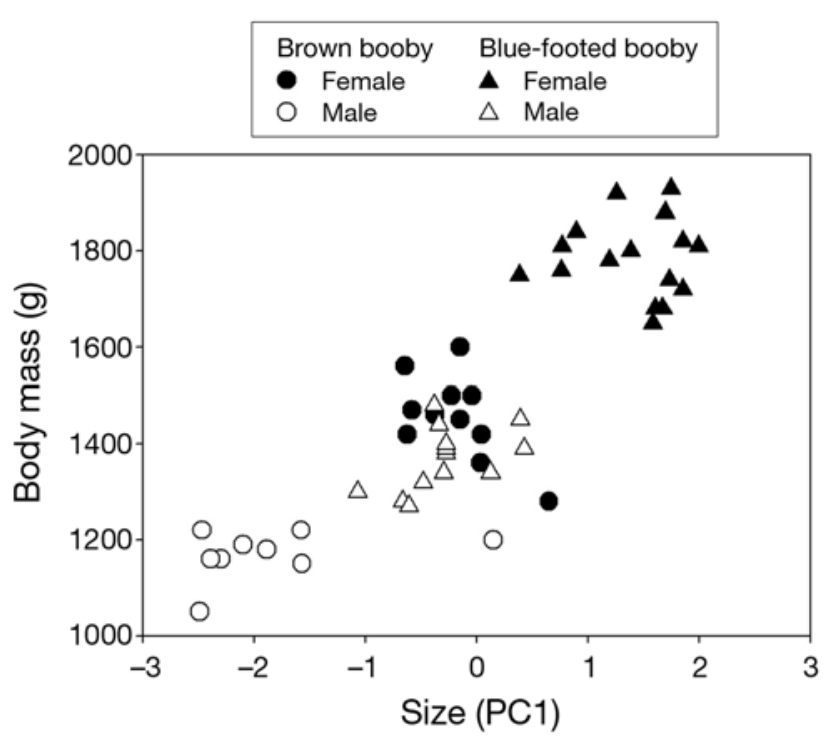

Fig. 1. Sula leucogaster and S. nebouxii. Relationship between size and body mass of male and female brown boobies and blue-footed boobies
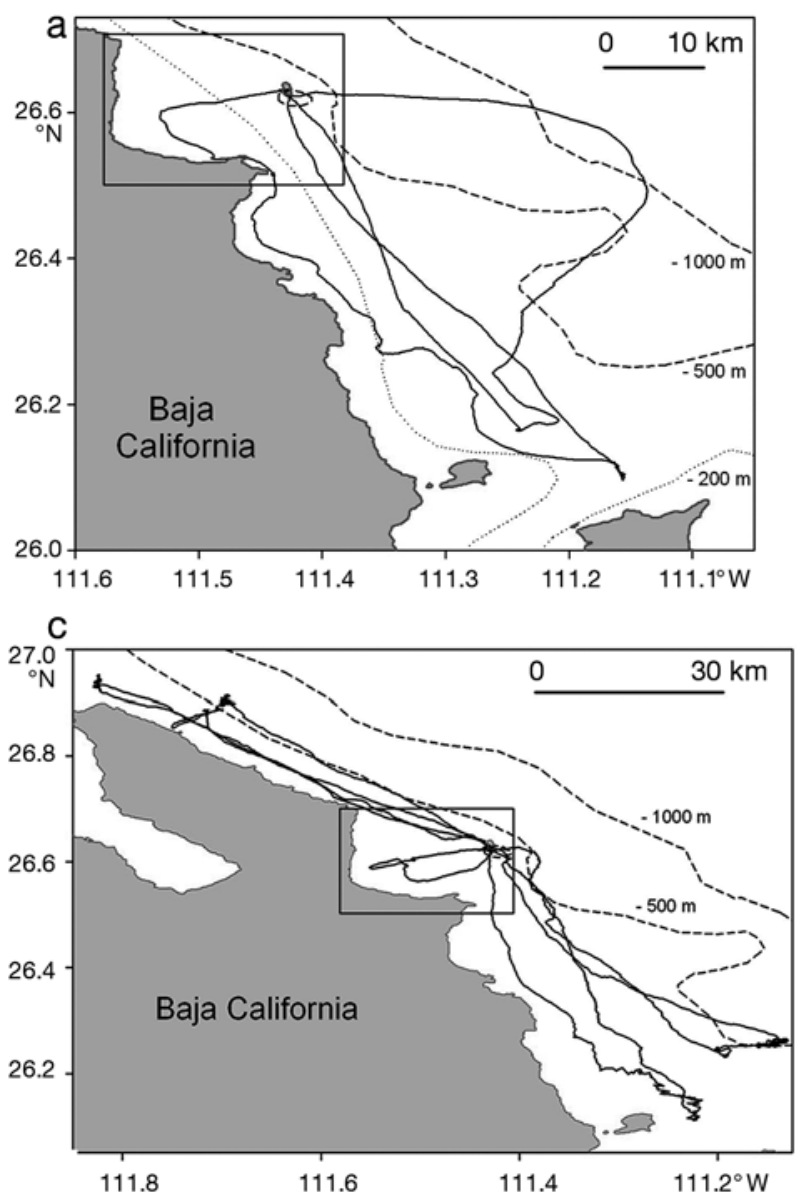

moved mainly to the west of the colony in 2 distinct manners: (1) short trips to a large gulf between Isla San Ildefonso and Baja California (hereafter called the Gulf of San Ildefonso; Fig. 2b,d), or (2) longer trips along the northern or southern coastal region of Baja California (Fig. 2a,c). All birds remained in waters shallower than $500 \mathrm{~m}$, and none moved to deeper waters east of the colony. Within a foraging zone, birds engaged in ARS as detected by fractal landscape analysis (Fig. 3). Several ARS of various sizes occurred within a foraging zone (Fig. 3). Although individuals spent only $\sim 13 \%$ of their at-sea time in small-scale ARS, $42 \%$ of landings were made within ARS, and $68 \%$ of the remaining landings were within $5 \mathrm{~min}$ of an ARS, i.e. at close distance.

There was high spatial overlap in foraging zones of both species (Fig. 4). For each species, ARS zones of males and females were mainly concentrated in the Gulf of San Ildefonso, but ARS zones of females were found much farther away from the colony in places never visited by males (Fig. 4).
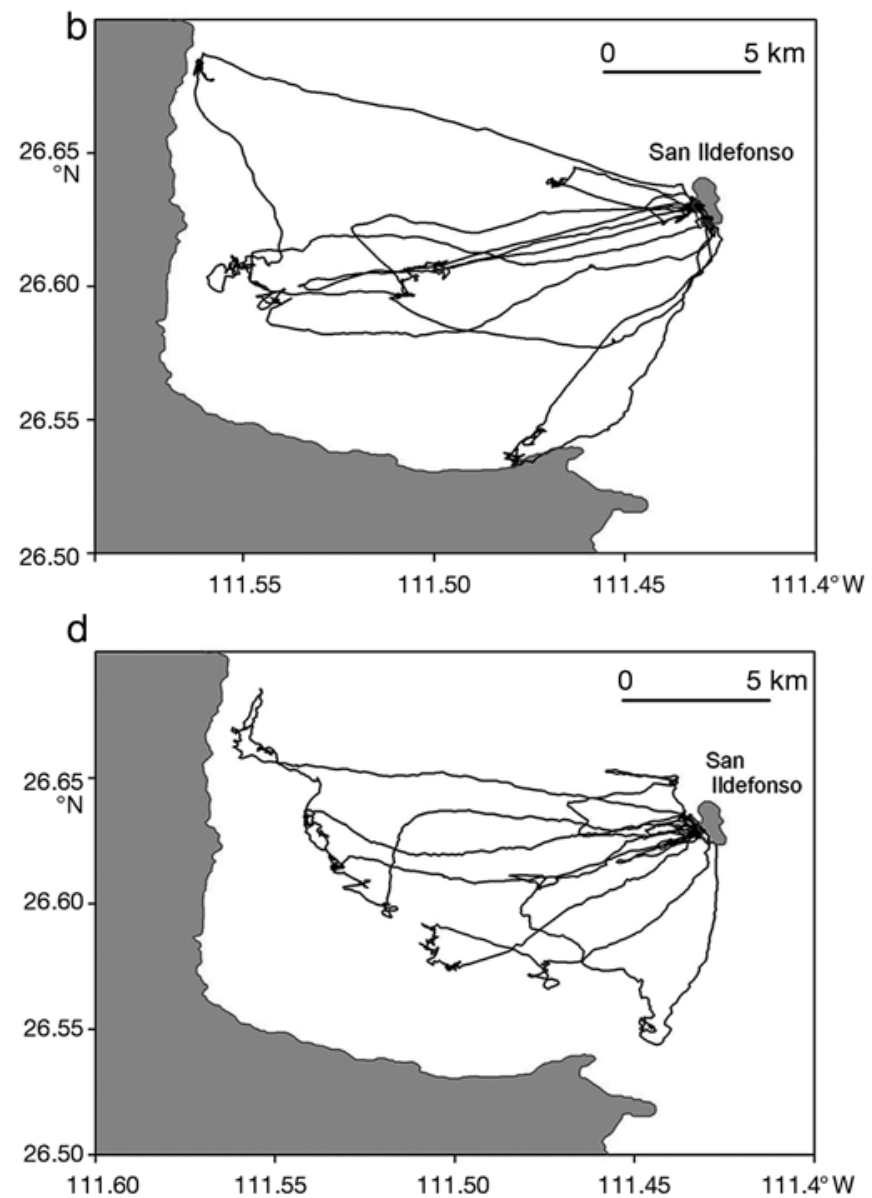

Fig. 2. Sula leucogaster and S. nebouxii. Foraging movements recorded by GPS at 10 s intervals: (a) long foraging trips of 2 female blue-footed boobies, and (b) short trips of 3 female and 1 male blue-footed boobies; (c) long trips of 3 female and 1 male (the longest trip to the north) brown boobies, and (d) short trips of male brown boobies. All birds were foraging from Isla San Ildefonso 


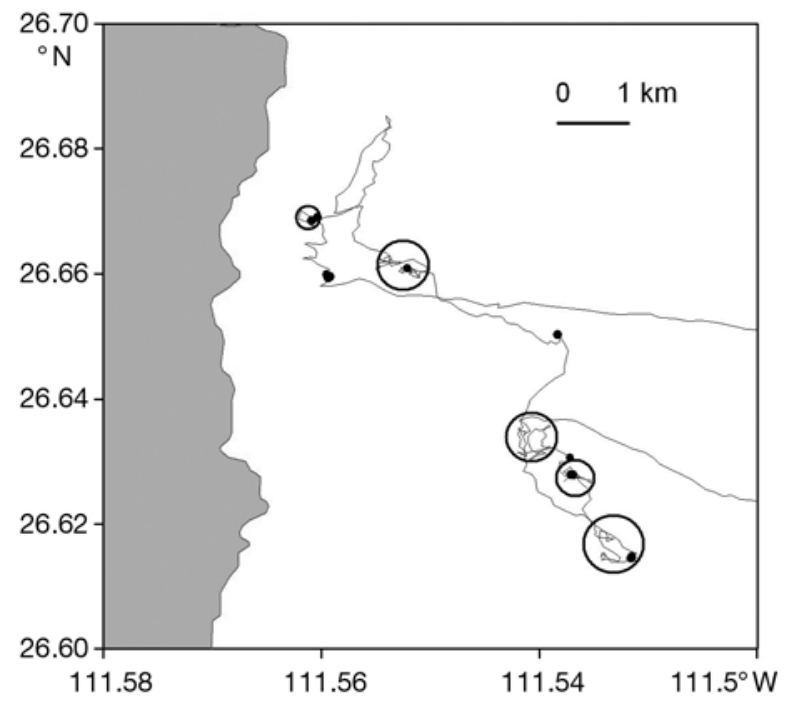

Fig. 3. Enlargement of a track of a female brown booby, showing the zones where area-restricted search was detected using the fractal landscape method. Black dots indicate when the bird was sitting on the water

\section{Foraging duration and range}

The duration, distance covered and maximum range of foraging trips were not different between species (Tables 2 \& 3). Females had longer foraging trips in both duration and distance travelled, as well as longer foraging ranges (Tables 2 \& 3). Similarly, distance to ARS zones from the colony were similar between species, but were longer in females than males for each species (Tables 2 \& 3). Female BB had larger ARS zones than males; however, time spent within an ARS or the number of ARS zones per trip did not differ be tween groups (Tables $2 \& 3$ ). When body mass and size were included as covariates, foraging range and distance covered were positively related to size, but not to mass (Tables $2 \& 3$ ).

Fig. 4. Sula leucogaster and S. nebouxii. (a) Tracks and (b) zones of area-restricted search (ARS) for male (white circles) and female (black circles) blue-footed and brown boobies. The size of the circles is proportional to the size of the ARS zone, but to be visible in the figure, the circle diameters have been multiplied by 5

\section{Flight speed, flight pattern, activity and diving}

Flight speeds were not significantly different between species, but they were significantly higher in females compared to males, and this difference was due to variation in body size (Tables $2 \& 3$ ). Stroke (flapping) frequency was higher for BB than for BFB and was mainly related to the size of individuals (Tables $2 \& 3$ ). The percentage of time spent on water during a complete trip was higher for BB than for BFB, but there were no differences between sexes or an influence of body mass or size (Tables $2 \& 3$ ). The number of landings per hour, an index of activity, was sim-
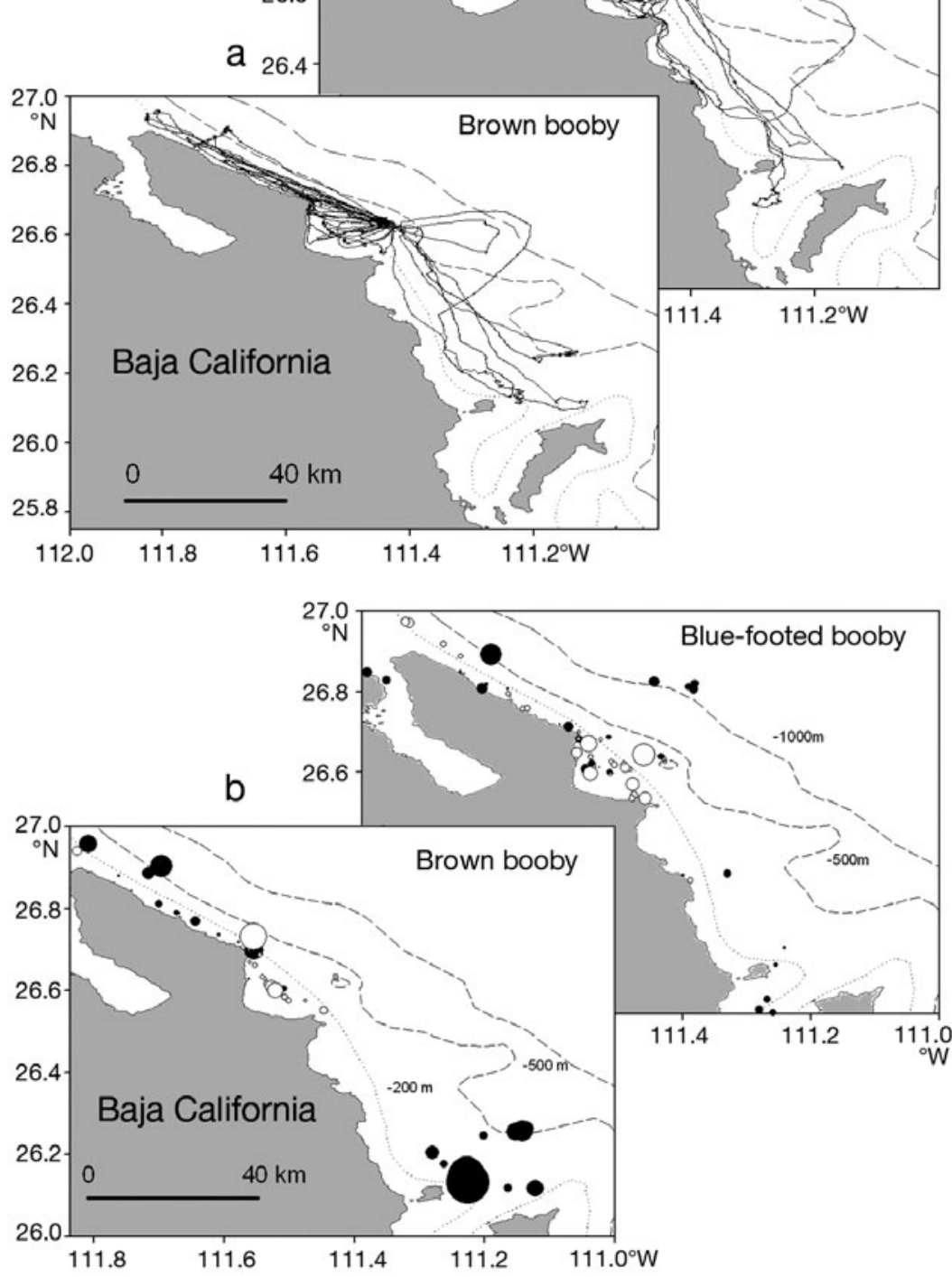
Table 2. Sula leucogaster and S. nebouxii. Foraging parameters of male and female blue-footed and brown boobies. Values are mean \pm SD (sample size). ARS: area-restricted search

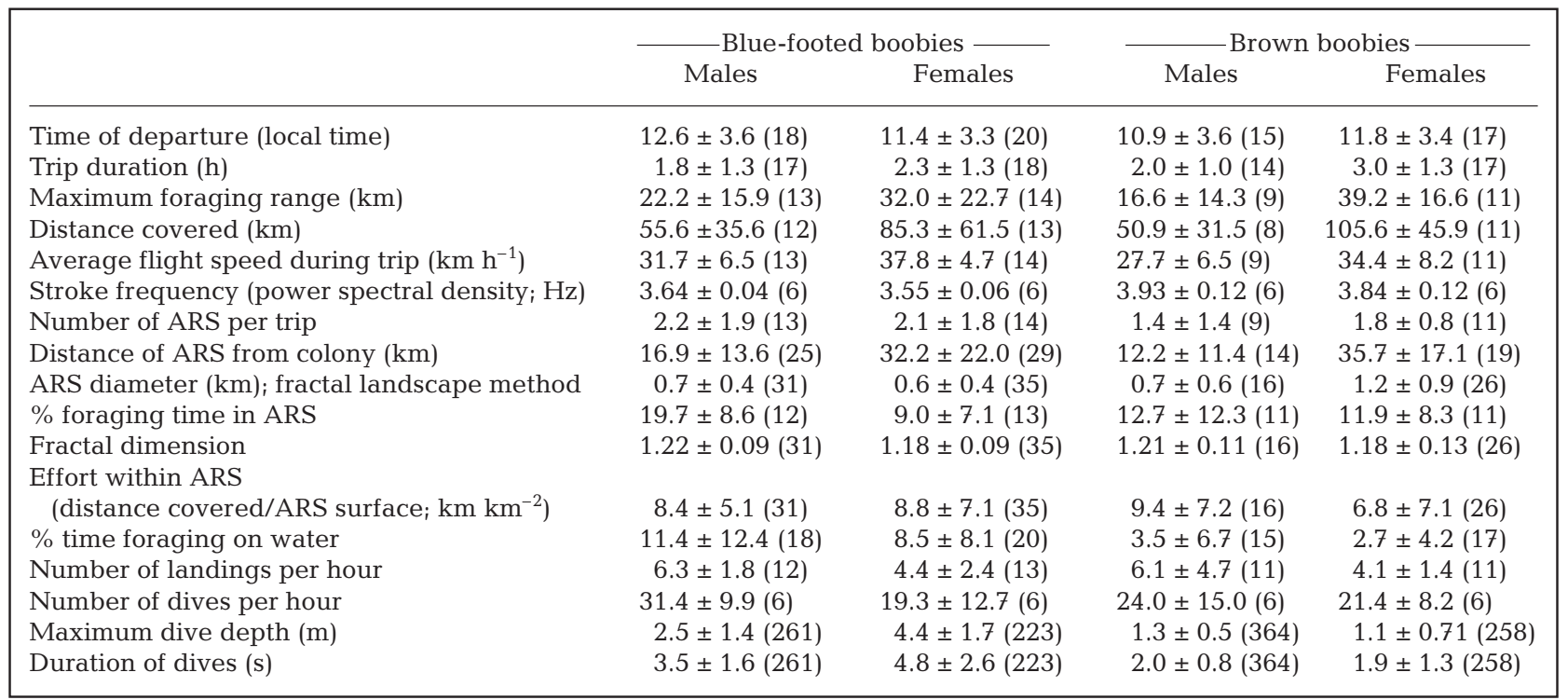

ilar between species, but different between sexes; males landed more often per unit of time than females, and this parameter was influenced by body mass (Tables 2 \& 3). Diving depths were deeper (Fig. 5) and dive durations longer in $\mathrm{BFB}$ compared to $\mathrm{BB}$; this difference was mainly the result of body mass differences between individuals (Tables $2 \& 3$ ). The number of dives per hour, a measure of foraging effort, was similar between sexes and species (Tables $2 \& 3$ ).

\section{Diet and isotopic signatures}

The diet of both species was dominated by one prey species, the sardine Sardinops caeruleus, with $90.4 \%$ of the samples containing this species. Of all samples, $77.4 \%$ contained only sardines, and the rest contained sardines and the fish species Selar crumenophtalmus or Etrumeus teres. In some samples, either or both of these 2 species were found exclusively, and in 1 female

Table 3. Results of general linear mixed models investigating the effects of sex and species, and body mass and size (as covariates) on foraging parameters of male and female blue-footed and brown boobies shown in Table 2. ARS: area-restricted search. Significant results in bold

\begin{tabular}{|c|c|c|c|c|c|c|c|c|c|}
\hline & \multirow[b]{3}{*}{ df } & \multirow{2}{*}{\multicolumn{2}{|c|}{ Species }} & & $\mathrm{L}$ & \multirow{2}{*}{\multicolumn{2}{|c|}{ Body mass }} & \multirow{2}{*}{\multicolumn{2}{|c|}{ Size }} \\
\hline & & & & \multicolumn{2}{|c|}{ Sex } & & & & \\
\hline & & $F$ & $\mathrm{p}$ & $F$ & $\mathrm{p}$ & $F$ & $\mathrm{p}$ & $F$ & $\mathrm{p}$ \\
\hline Time of departure & 38 & 2.3 & 0.201 & 0.4 & 0.593 & 4.0 & 0.144 & 0.2 & 0.757 \\
\hline Trip duration & 36 & 1.8 & 0.180 & 4.6 & 0.039 & 0.8 & 0.367 & 0.9 & 0.346 \\
\hline Maximum foraging range & 26 & 0.1 & 0.796 & 5.4 & 0.030 & 0.4 & 0.530 & 6.1 & 0.022 \\
\hline Distance covered & 24 & 0.4 & 0.529 & 6.8 & 0.017 & 0.8 & 0.590 & 5.1 & 0.046 \\
\hline Average flight speed during trip & 24 & 3.3 & 0.100 & 11.5 & 0.004 & 3.5 & 0.101 & 12.8 & 0.004 \\
\hline Stroke frequency (power spectral density) & 8 & 45.8 & $<0.001$ & 4.3 & 0.076 & 3.0 & 0.126 & 31.0 & 0.002 \\
\hline Number of ARS per trip & 24 & 1.6 & 0.229 & 0.7 & 0.418 & 0.1 & 0.959 & 0.2 & 0646 \\
\hline Distance of ARS from colony & 23 & 0.4 & 0.424 & 4.2 & 0.045 & 2.9 & 0.218 & 7.1 & 0.012 \\
\hline ARS diameter; fractal landscape method & 24 & 4.7 & 0.044 & 0.6 & 0.444 & 1.0 & 0.332 & 0.2 & 0.628 \\
\hline$\%$ foraging time in ARS & 24 & 0.8 & 0.403 & 8.9 & 0.020 & 2.1 & 0.137 & 5.1 & 0.061 \\
\hline Fractal dimension & 24 & 0.1 & 0.771 & 1.8 & 0.201 & 0.4 & 0.546 & 0.2 & 0.683 \\
\hline Effort within ARS (distance covered/ARS surface) & 24 & 1.9 & 0.179 & 0.1 & 0.762 & 2.0 & 0.199 & 0.3 & 0.556 \\
\hline$\%$ time foraging on water & 38 & 12.1 & $<0.001$ & 1.4 & 0.253 & 0.1 & 0.773 & 2.5 & 0.134 \\
\hline Number of landings per hour & 24 & 0.4 & 0.603 & 24.4 & 0.041 & 8.0 & 0.024 & 2.5 & 0.158 \\
\hline Number of dives per hour & 19 & 0.2 & 0.637 & 2.2 & 0.201 & 0.5 & 0.488 & 1.5 & 0.360 \\
\hline Maximum dive depth & 12 & 44.1 & $<0.001$ & 3.8 & 0.062 & 58.2 & $<0.001$ & 0.4 & 0.521 \\
\hline Duration of dives & 12 & 42.8 & $<0.001$ & 3.5 & 0.072 & 42.0 & $<0.001$ & 1.5 & 0.317 \\
\hline
\end{tabular}


BFB stomach, an unidentified scombrid species alone was found. There was no significant difference $\left(\chi^{2}{ }_{3}=\right.$ $2.2, \mathrm{p}=0.517$ ) in the percentage of sardines in the diet of male BFB (66.6\%), female BB (75\%), female BFB $(88.8 \%)$ or male BB $(92.8 \%)$.

Isotopic analyses showed that the stable carbon $\left(\delta^{13} \mathrm{C}\right)$ and nitrogen $\left(\delta^{15} \mathrm{~N}\right)$ isotopic compositions of blood during the breeding season were similar for male and female $\mathrm{BB}$ and $\mathrm{BFB}\left(\delta^{13} \mathrm{C}: F_{1,27}=0.2, \mathrm{p}=\right.$ 0.656 species effect, and $F_{1,27}=2.1, \mathrm{p}=0.158$ sex effect; $\delta^{15} \mathrm{~N}: F_{1,27}=0.4, \mathrm{p}=0.153$ species effect, and $F_{1,27}=1.9$, $\mathrm{p}=0.173$ sex effect; Fig. 6). Similarly, the analysis of feathers produced during moult indicates that the 2 sexes and species were feeding at similar trophic levels and in similar water masses (Fig. 6: $\delta^{13} \mathrm{C}: F_{1,56}=0.1$, $\mathrm{p}=0.932$ species effect, and $F_{1,56}=0.4, \mathrm{p}=0.510$ sex effect; $\delta^{15} \mathrm{~N}: F_{1,56}=2.8, \mathrm{p}=0.098$ species effect, and $F_{1,56}=0.1, \mathrm{p}=0.797$ sex effect; Fig. 6 ). The high vari-

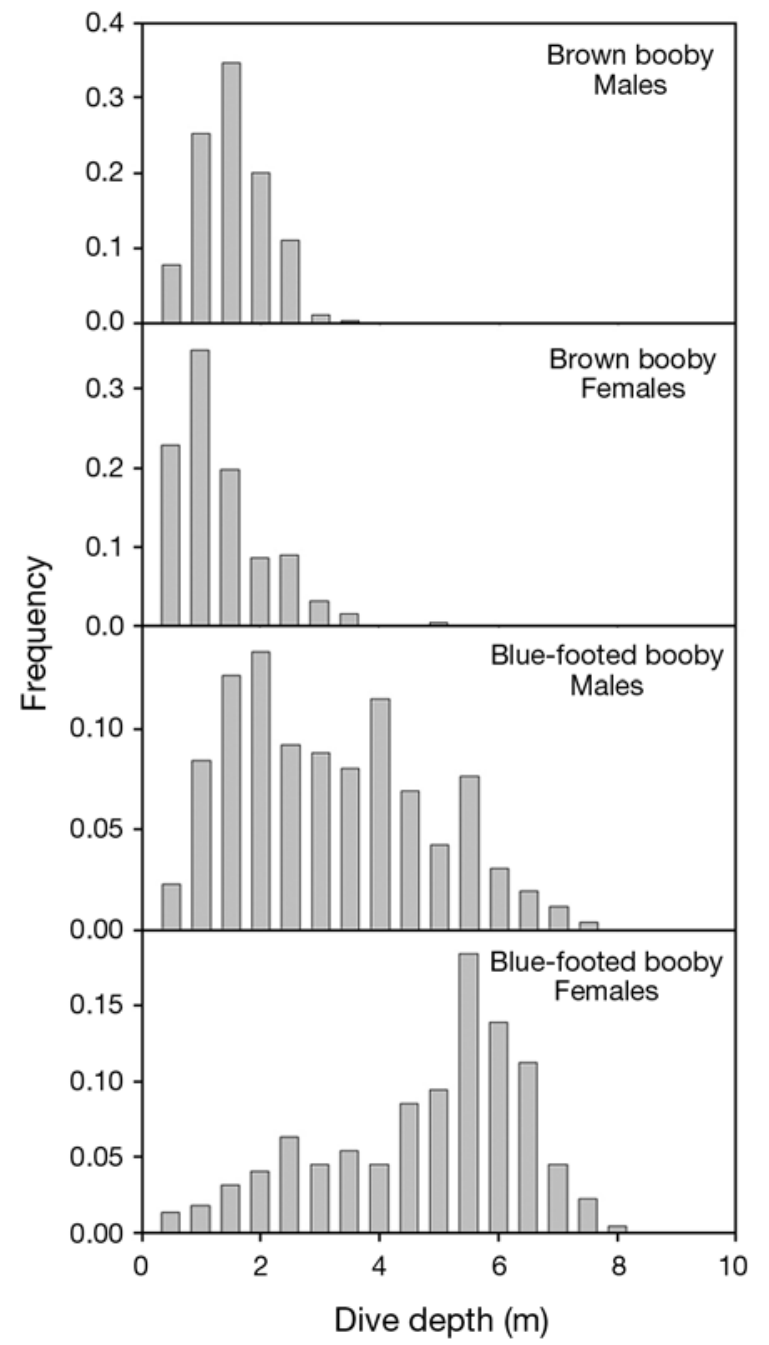

Fig. 5. Sula leucogaster and S. nebouxii. Frequency distribution of maximum diving depths of male and female brown and blue-footed boobies ance observed (Fig. 6) was due to the existence of groups with distinct isotopic signatures, suggesting variability in the prey consumed.

\section{DISCUSSION}

This study is the first to simultaneously compare the detailed foraging behaviour of both sexes in 2 closely related sympatric species of boobies, and in seabird species in general where only some foraging parameters have been studied in a few species before (e.g. González-Solís et al. 2000b, Lewis et al. 2005, Paredes et al. 2008). In addition, it is also the first to take into account size and body mass of individuals as covariates in a study on foraging parameters of seabirds. Although our study was based on small sample sizes due to logistic constraints, several clear results have emerged. The most important result is that differences between the sexes explained variation in foraging behaviour better than differences between species, and

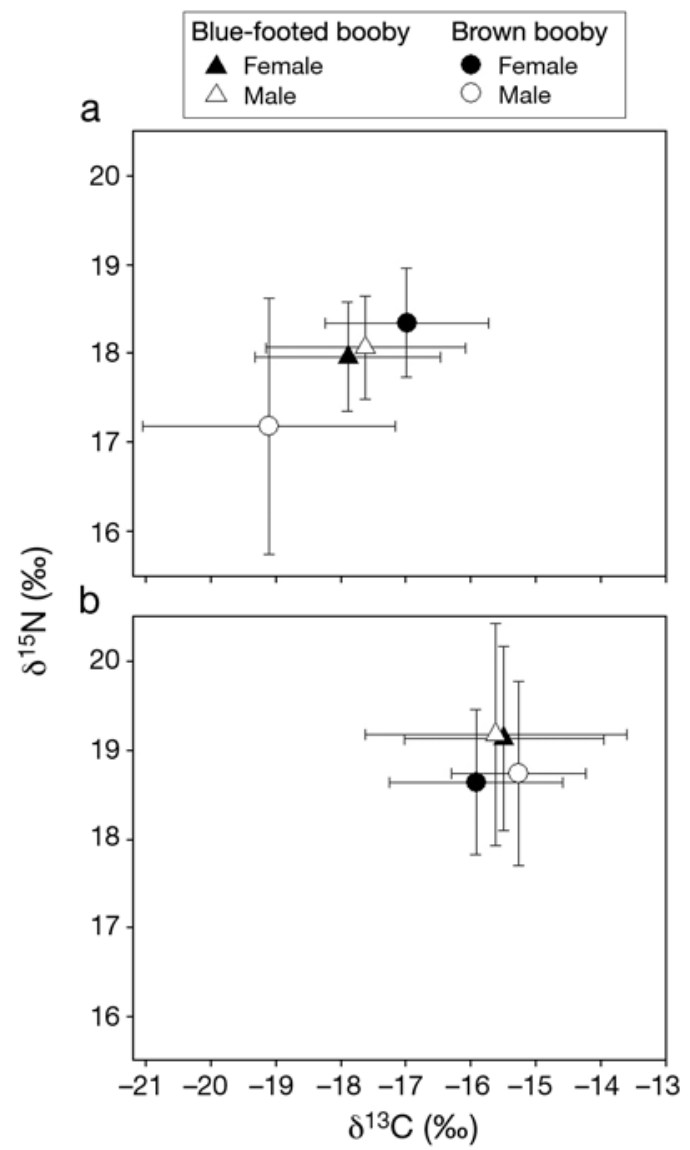

Fig. 6. Sula leucogaster and S. nebouxii. Stable carbon and nitrogen isotope values of (a) blood and (b) feathers of male and female blue-footed and brown boobies from Isla San Ildefonso. Values are mean $\pm \mathrm{SD}$ 
that several differences between sexes or species can be explained by differences in body size or body mass.

\section{Foraging context}

Both booby species breed in winter, when seasurface temperatures are coldest and chlorophyll (chl) a concentrations are highest in the Gulf of California, favouring the presence of large populations of sardines (Lluch-Cota et al. 2007). Nutrient enrichment within this geographic region is produced mainly by vertical mixing from tidal currents and wind-driven coastal upwelling (Roden \& Groves 1959). Overwhelmingly, sardines were the principal prey available and were consumed by both booby species, although anchoveta Cetengraulis mysticetus have been observed in the diets of BB in previous studies at Isla San Ildefonso (Mellink et al. 2001). The overlap in foraging zones of both species was extensive, as both $\mathrm{BB}$ and $\mathrm{BFB}$ concentrated their foraging effort in the Gulf of San Ildefonso. The relatively short foraging trip durations, compared to more pelagic booby species (red-footed and masked boobies, Weimerskirch et al. 2005, 2008) or even the same species at different locations (BFB: Nelson 1978, Anderson \& Ricklefs 1992, Zavalaga et al. 2007; BB: Nelson 1978, Lewis et al. 2005) suggests that food availability was relatively high close to the colony. Thus, the absence of clear segregation between species at Isla San Ildefonso was likely related to prey abundance; competition between species would have been stronger if food had been more limiting.

In the Gulf of California, coastal upwelling - forced by local wind conditions that are particularly strong in winter - creates important habitat for many top predators like large predatory fish, marine mammals and seabirds (Lluch-Cota 2000). During our study, boobies were often seen feeding in association with bottlenose dolphins Tursiops truncatus gilli that probably pushed sardines to the surface. The upwelling front was clearly visible from the surface, and the locations of ARS zones within the Gulf of San Ildefonso appeared to coincide with the location of the front (e.g. in Fig. 2d where ARS zones are aligned, presumably along the upwelling front). Boobies foraged mainly in these narrow upwelling fronts along the coast, which explains why their ARS zones were so tightly clustered just offshore. Within ARS zones, landings are probably associated with plunging (Fig. 3). Isolated landings may represent plunge dives on isolated prey or on small schools of fish that are rapidly disrupted by the plunging birds. In contrast, repeated plunging in ARS zones may represent foraging in larger, more stable schools, which are eventually maintained at depths reachable by marine mammals.

\section{Species differences}

In closely related species that breed sympatrically, it is generally expected that ecological segregation occurs to reduce competition (Ricklefs 1990). Several mechanisms have been found in seabird communities that allow ecological segregation, such as differences in foraging areas at sea (Croxall \& Prince 1980, Weimerskirch et al. 1986, 1993), or diving depths (Mori \& Boyd 2004), selection of different prey or prey of different size (Ashmole \& Ashmole 1967, Kato et al. 1996), timing of foraging (Cook et al. 2007) or time of reproduction (Harrison 1990). At Isla San Ildefonso, BFB and BB forage at sea during daylight hours, and both feed on average at similar trophic levels under the same oceanographic conditions. Isotopic feather analyses indicated that, during moult, which occurrs in boobies outside or at the end of the breeding season (Nelson 1978), no difference in average trophic level or oceanographic conditions between sexes and species occurs. However, average values show high variance during breeding and during moult. This high variance is not due to the small sample size, but to the existence of distinct groups with distinct isotopic signatures both in $\delta^{13} \mathrm{C}$ and $\delta^{15} \mathrm{~N}$, indicating that some individuals are feeding in different water masses on different prey, suggesting a specialisation of some individuals that is not apparent in the tracking data.

Although some foraging behaviours differed between species, the most noticeable difference was the maximum diving depths attained by BFB compared to BB (Fig. 6). The difference between both species is probably not related to their body mass differences alone, because there was little overlap in the depths attained by male BFB and female BB, which have a similar body mass (Table 1, Fig. 5). Behavioural differences may also play a role in the depths attained, because we observed that BFB fly at a higher altitude than $\mathrm{BB}$ and plunge dive from greater heights, which-combined with heavier bodies-provides greater momentum when entering the water (RopertCoudert et al. 2004). Another clear significant difference in foraging behaviour between species was the percentage of time spent on the water. BFB spent proportionally more time on the water than $B B$, suggesting some behavioural differences in foraging between species.

\section{Sex differences}

We expected interspecific differences to be greater than intersexual differences within a species. However, differences in foraging behaviour between sexes within the same species were more marked than the differences between species (Table 3). The major dif- 
ference between male and female boobies was that females foraged farther from the colony, had longer trip durations, flew greater distances at higher flight speeds, and travelled to more distant zones of ARS than males in both species. The differences in foraging behaviour between sexes were always more significant for BB than for BFB, whereas the differences in body mass and size between males and females were similar for both species, suggesting that there is no linear relationship between morphology and its effect on behaviour.

Previous studies have shown that BFB males and females had similar foraging trip durations in the Galapagos Islands (Anderson \& Ricklefs 1992) and in Peru (Zavalaga et al. 2007), and that females dove deeper and had different dive patterns than males (Zavalaga et al. 2007). In addition, female BB at Clipperton Island (Eastern Tropical Pacific) were observed at greater distances from the colony than males (Gilardi 1992), but in the Hawaiian Islands, females had shorter trips than males (Lewis et al. 2005). In San Pedro Martyr Island, another island in the Gulf of California, foraging trip duration of male and female BB were similar during the chick-feeding period, but females delivered heavier food loads (and more food overall) to chicks (Tershy 1998, Tershy \& Croll 2000). Sex-specific differences in foraging were also noted in red-footed boobies, where females foraged farther from the colonies (Weimerskirch et al. 2006) and were less active than males (Lewis et al. 2005, Weimerskirch et al. 2006). Conversely, there were no sex differences in most foraging parameters of masked boobies, except that females had higher foraging effort (i.e. dives per hour) and spent more time foraging than males (Weimerskirch et al. 2009). Overall, results of previous research as well as our study indicate that, in most localities, female boobies tend to forage farther from the nest and have longer foraging trips than males, but considerable variations exist between sites, which is likely due to variability in prey resources. Certainly, biological productivity is higher in the Gulf of California, given its more temperate oceanic conditions, compared to tropical and subtropical conditions where other booby species breed and where previous studies have been carried out (e.g. Europa Island, Northwest Hawaiian Islands, Clipperton Atoll).

During our study, we were not able to monitor nest attendance, which would have allowed us to relate foraging parameters and breeding involvement. Farther north, in the Gulf of California, female BB delivered more food overall to chicks than males (Tershy 1998, Tershy \& Croll 2000). Other studies have shown that larger females bring larger meals to chicks (Anderson \& Ricklefs 1992, Weimerskirch et al. 2006, 2009), which can be attributed in part to greater food storage capac- ity (Pierotti 1981, Shaffer et al. 2001), but also to shorter time spent with the chick compared to males. Since one parent always guards the small chick(s) when the other is at sea, the longer foraging trips of the partner results in longer periods on the nest, reducing further provisioning by the male to the chick(s). Thus, the longer foraging trips and larger size of females of both species suggest that, at our study site, females are probably the main provisioners, whereas males spend more time in nest attendance and nest defence (Guerra \& Drummond 1995, Tershy 1998, Tershy \& Croll 2000, Weimerskirch et al. 2006, 2009, see also Paredes et al. 2008 for alcids). Thus, the evolution of sexual size dimorphism in boobies may be related to the differences in roles that each parent plays in nest attendance and provisioning, and this may have led to differences in foraging strategies between the sexes. However, more studies relating detailed foraging behaviour and breeding duties are needed to validate this hypothesis.

Similar results whereby sex differences are more important than species differences have been shown in 2 sibling species of giant petrels, where males of both species forage over land whereas females are offshore feeders (González-Solís et al. 2000b). In that study, males and females occupied very distinct niches, with larger males foraging on seal carcasses on land and smaller females feeding on marine organisms, whereas differences between species within a particular sex were more subtle, with species foraging in slightly different water masses (González-Solís et al. 2000b). Similarities in foraging ecology between sexes of both species suggest that intersexual differences in trophic ecology probably evolved before the speciation of the 2 taxa (González-Solís et al. 2000b). However, it is important to point out that the similar results observed in boobies and in giant petrels, i.e. more extensive differences between sexes than between species in sympatric species, have probably evolved from completely different proximal causes.

\section{Influence of size and mass}

We used size and mass as covariates to examine whether they may explain part of the differences in foraging behaviour observed between individuals. Differences observed between sexes were explained by size for several parameters, in particular flight speed, foraging range and distance covered. As predicted by flight theory (Pennycuick 1989), flight speed was higher in larger individuals. The longer foraging range and distance covered could partly be the consequence of size differences. However, females fly 7 to $9 \%$ faster than males, but forage 32 to $59 \%$ farther than males, indicating that size accounts only for a small part of the 
variation in range and distance covered. In flying birds, stroke or flapping frequency are lower in larger individuals (Sato et al. 2007), and we indeed found a significant influence of size on stroke frequency in boobies. Body mass is also directly related to biomechanical constraints, and we showed that dive depths and time spent diving were positively related to the body mass of individuals. This is a logical result for a plunge-diving animal such as a booby that uses only the momentum of its plunge to attain depths, with heavier individuals attaining deeper depths when plunge diving (Ropert-Coudert et al. 2004).

\section{CONCLUSIONS}

We have shown that the differences in foraging behaviour in these 2 sympatric species are more prominent between the sexes than between species, and that size, and to a lesser extent body mass, explain several of the differences between individuals, in particular several sex differences. This underlines the importance of taking into account size as a covariable when sexspecific differences are examined in size-dimorphic species. In the case of our study on boobies, the greater differences in foraging behaviour observed between sexes than between species may be related to the superabundance of sardines consumed by both sexes and both species, which does not lead to niche differentiation between species. It would be interesting to test this hypothesis by comparing other populations of boobies breeding in sympatry, but in situations where food is scarce; in this case, we would predict that differences in foraging ecology between species would be at least as important as differences between sexes.

Acknowledgements. We thank SEP-CONACYT project SEP2004-C01-46806 and Fondo Mexicano para la Conservacion de la Naturaleza project E5-04-007 for the support to develop this research, Secretaria de Medio Ambiente y Recursos Naturales and its Direccion General de Vida Silvestre for the research permit SGPA/DGVS/01443-06. We thank F. Elorriaga Verplancken, V. Labrada Martagon and L. Cupa Cedillo from CICIMAR for their help in the field; V. M. Cota Gomez and J. de la Cruz Aguero in helping to identify stomach contents; and J. Fuentes for helping in sample preparation for isotope analysis. Funding was also made available by the Tagging of Pacific Pelagics program with support from the Sloan, Moore and Packard Foundations and the Office of Naval Research. We thank B. Tershy for helpful comments on the manuscript.

\section{LITERATURE CITED}

Anderson DJ, Ricklefs RE (1992) Brood size and food provisioning in masked and blue-footed boobies (Sula spp.). Ecology 73:1363-1374
Andersson M (1994) Sexual selection. Princeton University Press, Princeton, NJ

Andersson M, Norberg RÅ (1981) Evolution of reversed sexual size dimorphism and role partitioning among predatory birds, with a size scaling of flight performance. Biol J Linn Soc 15:105-130

Ashmole NP, Ashmole MJ (1967) Comparative feeding ecology of seabirds of a tropical oceanic island. Peabody Museum of Natural History, Yale University, Bulletin 24. Peabody Museum of Natural History, New Haven, CT

Bligh EG, Dyer WJ (1959) A rapid method of total lipid extraction and purification. Can J Biochem Physiol 37:911-917

> Bowers MA, Smith HD (1979) Differential habitat utilization by sexes of the deer mouse, Peromyscus maniculatus. Ecology 60:869-875

Clutton-Brock TH, Iason GR, Guinness FE (1987) Sexual segregation and density-related changes in habitat use in male and female deer (Cervus elaphus). J Zool 211: 275-289

Cook T, Cherel Y, Bost CA, Tremblay Y (2007) Chick-rearing Crozet shags (Phalacrocorax melanogenis) display sexspecific foraging behaviour. Antarct Sci 19:55-63

Croxall JP, Prince PA (1980) Food, feeding ecology and ecological segregation of seabirds at South Georgia. Biol J Linn Soc 14:103-131

Fitch JE (1966) Additional fish remains, mostly otoliths, from a Pleistocene deposit at Playa del Rey, California. Los Angeles County Mus Contrib Sci 119:1-16

Fitch JE, Brownell RL (1968) Fish otoliths in cetacean stomachs and their importance in interpreting feeding habits. J Fish Res Board Can 25:2561-2574

Gilardi JD (1992) Sex-specific foraging distributions of brown boobies in the eastern tropical Pacific. Colon Waterbirds 15:148-151

González-Solís J, Croxall JP, Wood AG (2000a) Sexual dimorphism and sexual segregation in foraging strategies of northern giant petrels Macronectes halli during incubation. Oikos 90:390-398

González-Solís J, Croxall JP, Wood AG (2000b) Foraging partitioning between giant petrels Macronectes spp. and its relationship with breeding population changes at Bird Island, South Georgia. Mar Ecol Prog Ser 204:279-288

Gray CM, Hamer KC (2001) Food-provisioning behaviour of male and female Manx shearwaters. Anim Behav 62: $117-121$

> Guerra M, Drummond H (1995) Reversed sexual size dimorphism and parental care: minimal division of labour in the blue-footed booby. Behaviour 132:479-496

Harrison CS (1990) Seabirds of Hawaii: natural history and conservation. Cornell University Press, Ithaca, NY

> Hedrick AV, Temeles EJ (1989) The evolution of sexual dimorphism in animals: hypotheses and tests. Trends Ecol Evol 4:136-138

> Hertel F, Ballance LT (1999) Wing ecomorphology of seabirds from Johnston Atoll. Condor 101:549-556

Hobson KA, Gibbs HL, Gloutney ML (1997) Preservation of blood and tissue samples for stable-carbon and stablenitrogen isotope analysis. Can J Zool 75:1720-1723

Kato A, Nishiumi I, Naito Y (1996) Sexual differences in the diet of king cormorants at Macquarie Island. Polar Biol 16: 75-77

Kato A, Watanuki Y, Shaughnessy P, Le Maho Y, Naito Y (1999) Intersexual differences in the diving behaviour of foraging subantarctic cormorant (Phalacrocorax albiventer) and Japanese cormorant (P. filamentosus). C R Acad Sci Paris 322:557-562 
LeBoeuf BJ, Crocker DE, Costa DP, Blackwell SB, Webb PM, Houser DS (2000) Foraging ecology of northern elephant seals. Ecol Monogr 70:353-382

Lewis S, Benvenuti S, Dall'Antonia L, Griffiths R and others (2002) Sex-specific foraging behaviour in a monomorphic seabird. Proc R Soc Lond B Biol Sci 269:1687-1693

Lewis S, Schreiber EA, Daunt F, Schenk GA and others (2005) Sex-specific foraging behaviour in tropical boobies: Does size matter? Ibis 147:408-414

Lluch-Cota SE (2000) Coastal upwelling in the eastern Gulf of California. Oceanol Acta 23:731-740

Lluch-Cota SE, Aragón-Noriega EA, Arreguín-Sánchez F, Aurioles-Gamboa D and others (2007) The Gulf of California: review of ecosystem status and sustainability challenges. Prog Oceanogr 73:1-26

Mellink E (2000) Breeding of brown boobies in the Gulf of California: seasonality and apparent effects of El Niño. Waterbirds 23:494-499

Mellink E, Dominguez J, Luévano J (2001) Diet of eastern Pacific brown boobies Sula leucogaster brewsteri on Isla San Jorge, north-eastern Gulf of California, and an April comparison with diets in the middle Gulf of California. Mar Ornithol 29:23-28

Mori Y, Boyd IL (2004) Segregation of foraging between two sympatric penguin species: Does rate maximisation make the difference? Mar Ecol Prog Ser 275:241-249

Mueller HC (1990) The evolution of reversed sexual dimorphism in size in monogamous species of birds. Biol Rev Camb Philos Soc 65:553-585

Nelson B (1978) The Sulidae: gannets and boobies. Oxford University Press, Oxford

Newton I (1979) Population ecology of raptors. Poyser, Berkhamsted

Paredes R, Jones IL, Boness DL, Tremblay Y, Renner M (2008) Sex-specific differences in diving behaviour of two sympatric Alcini species: thick-billed murres and razorbills. Can J Zool 86:610-622

Pennycuick CJ (1989) Bird flight performance: a practical calculation manual. Oxford Science Publications, Oxford University Press, Oxford

> Phillips RA, Silk JRD, Phalan B, Catry P, Croxall JP (2004) Seasonal sexual segregation in two Thallassarche albatross species: competitive exclusion, reproductive role specialization or foraging niche divergence. Proc R Soc Lond B Biol Sci 271:1283-1291

Pianka ER (1981) Competition and niche theory. In: May RM (ed) Theoretical ecology, 2nd edn. Blackwell, Oxford, p 167-196

Pierotti R (1981) Male and female parental roles in the western gull under under different environmental conditions. Auk 98:532-549

Ricklefs RE (1990) Ecology, 3rd edn. W. H. Freeman, New York

Roden GI, Groves GW (1959) Recent oceanographic investigations in the Gulf of California. J Mar Res 18:10-35

Ropert-Coudert Y, Grémillet D, Ryan P, Kato A, Naito Y, Le Maho Y (2004) Between air and water: the plunge dive of the Cape Gannet Morus capensis. Ibis 146:281-290
Sato K, Watanuki Y, Takahashi A, Miller PJO and others (2007) Stroke frequency, but not swimming speed, is related to body size in free-ranging seabirds, pinnipeds and cetaceans. Proc R Soc Lond B Biol Sci 274:471-477

Schoener T (1967) The ecological significance of sexual dimorphism in size in the lizard Anolis conspersus. Science 155:474-477

Selander RK (1966) Sexual dimorphism and differential niche utilization in birds. Condor 68:113-151

Shaffer SA, Weimerskirch H, Costa DP (2001) Functional significance of sexual dimorphism in wandering albatrosses Diomedea exulans. Funct Ecol 15:203-210

Shine R (1989) Ecological causes for the evolution of sexual dimorphism: a review of the evidence. Q Rev Biol 64: $419-461$

Steiner I, Bürgi C, Werffeli S, Dell'Omo G and others (2000) A GPS logger and software for analysis of homing in pigeons and small mammals. Physiol Behav 71:589-596

Tershy BR (1998) Sexual dimorphism in the brown booby. PhD thesis, Cornell University, Ithaca

Tershy BR, Croll DA (2000) Parental investment, adult sex ratios, and sexual selection in a socially monogamous seabird. Behav Ecol Sociobiol 48:52-60

Tremblay Y, Roberts AJ, Costa DP (2007) Fractal landscape method: an alternative approach to measuring arearestricted searching behaviour. J Exp Biol 210:935-945

> Watanuki Y, Niizuma Y, Gabrielsen GW, Sato K, Naito Y (2003) Stroke and glide of wing-propelled divers: deep diving seabirds adjust surge frequency to buoyancy change with depth. Proc R Soc Lond B Biol Sci 270: 483-488

> Weimerskirch H, Jouventin P, Stahl JC (1986) Comparative ecology of the six albatross species breeding on the Crozet islands. Ibis 128:195-213

Weimerskirch H, Salamolard M, Sarrazin F, Jouventin P (1993) Foraging strategy of wandering albatrosses through the breeding season: a study using satellite telemetry. Auk 110:325-342

Weimerskirch H, Le Corre M, Ropert-Coudert Y, Kato A, Marsac F (2005) The three-dimensional flight of redfooted boobies: adaptations to foraging in a tropical environment. Proc R Soc Lond B Biol Sci 272:53-61

Weimerskirch H, Le Corre M, Ropert-Coudert Y, Kato A, Marsac F (2006) Sex-specific foraging behaviour in a seabird with reversed sexual dimorphism, the red-footed booby. Oecologia 146:681-691

Weimerskirch H, Le Corre M, Bost CA (2008) Foraging strategy of masked boobies from the largest colony in the world: relationship with environmental conditions and fisheries. Mar Ecol Prog Ser 362:291-302

Weimerskirch H, Le Corre M, Gadenne H, Pinaud D, Kato A, Ropert-Coudert Y, Bost CA (2009) Relationship between reversed sexual dimorphism, breeding investment and foraging ecology in a pelagic seabird, the masked booby. Oecologia 161:637-649

Z Zavalaga CB, Benvenuti S, Dall'Antonia L, Emslie SD (2007) Diving behaviour of blue-footed boobies Sula nebouxii in northern Peru in relation to sex, body size and prey type. Mar Ecol Prog Ser 336:291-303

Submitted: September 16, 2008; Accepted: February 18, 2009

Proofs received from author(s): March 4, 2009
Editorial responsibility: Jacob González-Solís, Barcelona, Spain 